\title{
Promotion of hematogenous metastatic potentials in human KB carcinoma cells with overexpression of cyclooxygenase-2
}

\author{
EMI SEGAWA, HIROMITSU KISHIMOTO, KAZUKI TAKAOKA, KAZUMA NOGUCHI, \\ SUSUMU HASHITANI, KAZUNARI SAKURAI and MASAHIRO URADE \\ Department of Oral and Maxillofacial Surgery, Hyogo College of Medicine, \\ 1-1 Mukogawa-cho, Nishinomiya, Hyogo 663-8501, Japan
}

Received January 14, 2010; Accepted March 29, 2010

DOI: $10.3892 /$ or_00000915

\begin{abstract}
To understand the role of cyclooxygenase (COX)-2 in metastatic potential of oral cancer, COX-2 overexpressing $\mathrm{KB} / \mathrm{COX}-2$ cells were inoculated orthotopically into the masseter muscle or injected into the left cardiac ventricle of nude mice. $\mathrm{KB} / \mathrm{COX}-2$ showed about 4 -fold increase of COX-2 protein expression as compared to $\mathrm{KB} / \mathrm{Neo}$ which was a mock transfected control. In orthotopic inoculation, metastasis to the regional lymph nodes occurred in 2 out of 15 mice, and metastasis to the lung in 3 out of 15 mice. On the other hand, in intra-cardiac injection, hematogenous metastasis to the lung and bone occurred in 8 out of 10 mice in $\mathrm{KB} / \mathrm{COX}-2$, but no metastasis occurred except for only one metastasis to the femur bone out of 10 mice in $\mathrm{KB} / \mathrm{Neo}$. Treatment of KB/COX-2 with COX-2 small interfering RNA (siRNA) inhibited the colony formation but not cell growth in vitro, and suppressed tumorigenicity and hematogenous metastasis in nude mice. When expression of adhesion molecules such as E-cadherin, $\alpha$-catenin, $\beta$-catenin and CD44 was examined, there was no difference in $\alpha$ - and $\beta$-catenin between the cells. However, expression of E-cadherin was detected in $\mathrm{KB} / \mathrm{Neo}$, but not in $\mathrm{KB} / \mathrm{COX}-2$. In contrast, expression of CD44 was markedly increased in $\mathrm{KB} / \mathrm{COX}-2$ as compared to $\mathrm{KB} / \mathrm{Neo}$. Treatment with $\mathrm{COX}-2$ siRNA resulted in suppression of $\mathrm{CD} 44$ expression and detectable expression of E-cadherin in $\mathrm{KB} / \mathrm{COX}-2$. These findings suggested that overexpression of COX-2 increased hematogenous metastasis, at least in $\mathrm{KB}$ cells, via down-regulating E-cadherin and up-regulating CD44 expression.
\end{abstract}

Correspondence to: Dr Hiromitsu Kishimoto, Department of Oral and Maxillofacial Surgery, Hyogo College of Medicine, 1-1 Mukogawa-cho, Nishinomiya, Hyogo 663-8501, Japan

E-mail: kisihiro@hyo-med.ac.jp

Abbreviations: COX-2, cyclooxygenase-2; siRNA, small interfering RNA; PG, prostaglandin; MMP, matrix metalloproteinase; TIMP, tissue inhibitor of metalloproteinases

Key words: CD44, COX-2, metastasis, oral cancer, siRNA

\section{Introduction}

Cyclooxygenase (COX)-2 is an enzyme induced by mitogens, cytokines and growth factors of epithelial cells and plays an important role in prostaglandin (PG) production. Overexpression of COX-2 has been reported in a variety of cancers (1-4) including head and neck cancer (5-8). Recently, a human colon cancer cell line transfected with a COX-2 expression vector acquired increased invasiveness and metastatic potential with activation of matrix metalloproteinase (MMP) (9). A correlation between COX-2 overexpression and hematogenous metastasis of colorectal cancer was also demonstrated (10). These findings suggest that COX-2 overexpression is involved in colon cancer metastasis. In head and neck cancer, however, the significance of COX-2 overexpression in metastasis is poorly understood.

We have already shown that $\mathrm{KB} / \mathrm{COX}-2$, which was established by stable transfection with full length COX-2 cDNA to human KB carcinoma cells, showed elevated $\mathrm{PGE}_{2}$ production, cell migration and invasion as compared to mock transfected control, $\mathrm{KB} / \mathrm{Neo}$. Furthermore, it was found that $\mathrm{KB} / \mathrm{COX}-2$ increased tumorigenicity, tumor growth and local tumor invasion in nude mice. These effects were apparently modulated by up-regulation of MMPs and Rho family small guanosine triphosphatases (GTPases) and down-regulation of tissue inhibitor of metalloproteinase (TIMP) activities (11).

The aim of this study was to investigate the metastatic potential in nude mice using $\mathrm{KB} / \mathrm{COX}-2$. In addition, to assess the molecular and cellular effects on COX-2 gene silencing, we knocked down COX-2 using small interfering RNA (siRNA) in KB/COX-2 cells, and examined tumorigenicity, tumor growth, invasion and metastasis. KB/COX-2 cells were inoculated in the masseter muscle as an orthotopic spontaneous metastasis model, and intra-cardiac injection was performed as a hematogenous metastasis model in nude mice.

\section{Materials and methods}

Cell lines. Two cell lines, $\mathrm{KB} / \mathrm{COX}-2$ and $\mathrm{KB} / \mathrm{Neo}$, were used in this study as described previously (11). We isolated a clone which highly expressed COX-2 and designated as $\mathrm{KB} / \mathrm{COX}-2$, and a mock-transfected clone, $\mathrm{KB} / \mathrm{Neo}$ as a 
control. These cell lines were routinely subcultured in Dulbecco's modified Eagle's MEM (DMEM, Nissui Pharmaceutical Co., Tokyo, Japan).

Transfection of siRNAs. KB/COX-2 was plated in DMEM supplemented with $10 \%$ FBS for $24 \mathrm{~h}$, then transfected with 5 nM of siRNA using Lipofectamine ${ }^{\mathrm{TM}} 2000$ (Invitrogen Co., Carlsbad, CA, USA) according to the manufacturer's protocol. SMART pool siRNA targeting COX-2 (M-004557-00) and control siRNA, Lamin A/C (D-001050-01-20), were purchased from Dharmacon Inc. (Lafayette, CO, USA). We used the cells cultured for $24 \mathrm{~h}$ after transfection of siRNAs.

Animals and animal care. Female BALB/c nu/nu mice (6 weeks old) were purchased from Oriental Yeast Ltd. (Osaka, Japan). The mice were maintained under pathogen-free conditions and were handled in accordance with the Guidelines for Animal Experiments of Hyogo College of Medicine.

Tumorigenicity and metastasis assays. The cells were trypsinized, washed once with DMEM and resuspended in $0.1 \mathrm{ml}$ of $\mathrm{Mg}^{2+}$ - and $\mathrm{Ca}^{2+}$-free phosphate-buffered saline [PBS(-)] for transplantation in nude mice. For subcutaneous or orthotopic inoculation, cells were inoculated into the flank or the masseter muscle of mice. For intra-cardiac injection, cells were slowly injected into the left cardiac ventricle of mice. Then, mice were examined for the development of tumors and measured for body weight once a week. The tumor size was measured by using calipers. Tumor volume was calculated by the following formula: volume $\left(\mathrm{mm}^{3}\right)=$ $a^{2} x b / 2$, where $a$ is the width in $\mathrm{mm}$ and $b$ is the length in $\mathrm{mm}$ (12). Mice were sacrificed and dissected 7 weeks after cell inoculation. Tumors formed at inoculated site, regional lymph nodes, lungs and other organs were subjected for metastatic analysis.

Western blot analysis. Cell lysates were submitted to Western blot analysis as described previously (13). The primary antibodies used were goat polyclonal antibody against COX-2 and actin (Santa Cruz Biotechnology, Santa Cruz, CA, USA), mouse monoclonal antibody against E-cadherin (Chemicon International Inc., Temecula, CA, USA) and CD44 (Thermo Scientific, Fremont, CA, USA) and rabbit polyclonal antibody against $\alpha$-catenin and $\beta$-catenin (Santa Cruz Biotechnology). The secondary antibodies used were anti-goat, anti-mouse or anti-rabbit IgGs conjugated with alkaline phosphatase (Santa Cruz Biotechnology). Actin was used as an internal control.

$R N A$ preparation and real-time PCR. Tumor which became about $5 \mathrm{~mm}$ in diameter was snap-frozen. Total RNA was isolated using the RNeasy Mini kit (Qiagen, Valencia, CA, USA) and cDNAs were generated by using a First-Strand cDNA Synthesis kit (Amersham Biosciences, Piscataway, NJ, USA) with $2 \mu \mathrm{g}$ of total RNA and oligo(dT) (Amersham Biosciences). All reagents required for real-time PCR were from Applied Biosystems (Foster City, CA, USA). Oligonucleotide primer pairs and fluorescent probes for COX-2 and GAPDH were designed using a primer design program (Primer Express, Applied Biosystems) and were obtained from Integrated DNA Technologies (Coralville, IA, USA).
The real-time PCR was carried out using the TaqMan Gene Expression Assays products on an ABI PRISM 7900 HT Sequence Detection System (Applied Biosystems) according to the manufacturer's protocol as described previously (14).

Histological studies. Tissues specimens were fixed in $10 \%$ formalin, embedded in paraffin and cut into $4-\mu \mathrm{m}$-thick sections according to conventional procedures. Histological examination was performed by H\&E stain and evaluated by light microscopy for the number of regional lymph nodes or distant metastases in the largest sagittal cross section.

Clonogenic assay. Clonogenic assay was performed by plating an appropriate number of cells $\left(10^{2}-10^{3}\right.$ cells $\left./ \mathrm{ml}\right)$ into $100-\mathrm{mm}$ culture dishes. After 14 days, cells were fixed and stained with $1 \%$ crystal violet, and colonies containing $>50$ cells were counted.

$P G E_{2}$ immunoassay and motility assay. $\mathrm{PGE}_{2}$ immunoassay was performed as indicated in a protocol of Prostaglandin E2 EIA kit (Cayman Chemical, Ann Arbor, MI, USA) as described previously (15). Wound healing assay was performed using 60-mm fibronectin-coated dishes (Asahi Techno Glass Co., Tokyo, Japan) and cell invasion assay was carried out using BioCoat Matrigel Invasion Chambers (BectonDickinson Labware, Bedford, MA, USA) as described previously (11).

Statistical analysis. Statistical analysis was performed by using the Student's t-test and Fisher's exact test. Differences were considered significant at $\mathrm{p}$-value $<0.05$.

\section{Results}

Suppression of $C O X-2$ expression in $\mathrm{KB} / \mathrm{COX}-2$ cells by treatment with siRNA of $C O X-2$. We examined the suppressive effect of COX-2 siRNA on COX-2 protein and mRNA expression in $\mathrm{KB} / \mathrm{COX}-2$ cells. COX-2 siRNA treatment markedly suppressed the expression of $\mathrm{COX}-2$ protein in $\mathrm{KB} / \mathrm{COX}-2$ cells, and this suppressive effect continued significantly until day 7 (Fig. 1A). Using real-time PCR, expression level of COX-2 mRNA was also examined. KB/COX-2 cells showed about a 50-fold increase of COX-2 mRNA expression as compared to $\mathrm{KB} / \mathrm{Neo}$, whereas $\mathrm{COX}-2$ siRNA-treated KB/COX-2 showed about $98 \%$ decrease of COX-2 mRNA expression as compared to control siRNA-treated KB/COX-2 (Fig. 1B). KB/COX-2 cells treated with siRNA of either COX-2 or control showed a similar growth rate, suggesting no contribution of COX-2 in cell growth of KB/COX-2.

In the $\mathrm{PGE}_{2}$ production, $\mathrm{COX}-2$ siRNA-treated $\mathrm{KB} /$ COX-2 cells showed about $85 \%$ inhibition as compared to control siRNA-treated (Fig. 2A). In addition, COX-2 siRNAtreated $\mathrm{KB} / \mathrm{COX}-2$ cells showed decreased cell migration and filled the scratch wound slightly slower than the control siRNA-treated cells (Fig. 2B). COX-2 siRNA-treated $\mathrm{KB} / \mathrm{COX}-2$ cells demonstrated a significant decreased ability to migrate through Matrigel invasion chambers as compared to control siRNA-treated cells (Fig. 2C).

Increased CD44 expression by COX-2 overexpression. Since we confirmed the suppressive effect of COX-2 siRNA on 
A

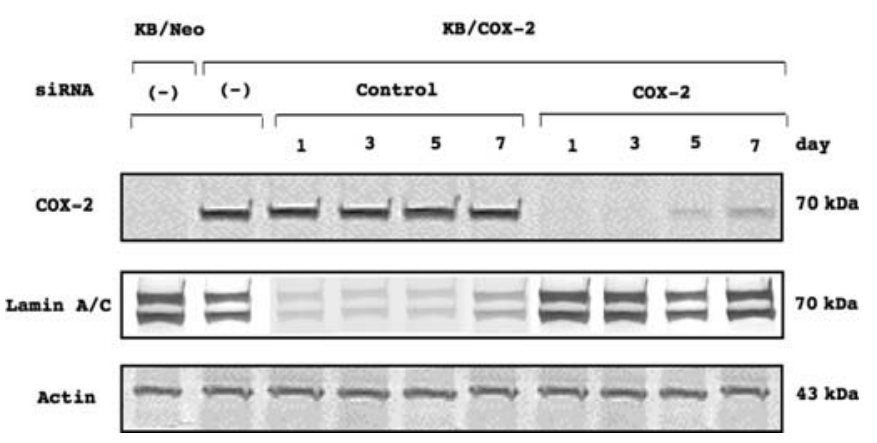

B

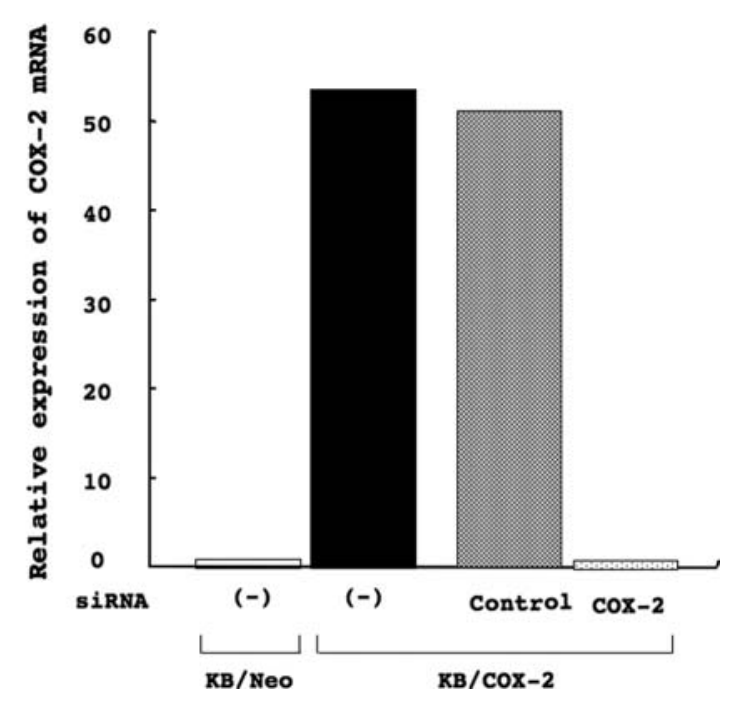

Figure 1. Expression of COX-2 in $\mathrm{KB} / \mathrm{Neo}$ and $\mathrm{KB} / \mathrm{COX}-2$ cells and inhibition by COX-2 siRNA treatment. (A) Expression of COX-2 protein in Western blot analysis. Time course study with COX-2 siRNA in KB/COX-2 was performed. (B) Expression of COX-2 mRNA in real-time PCR.

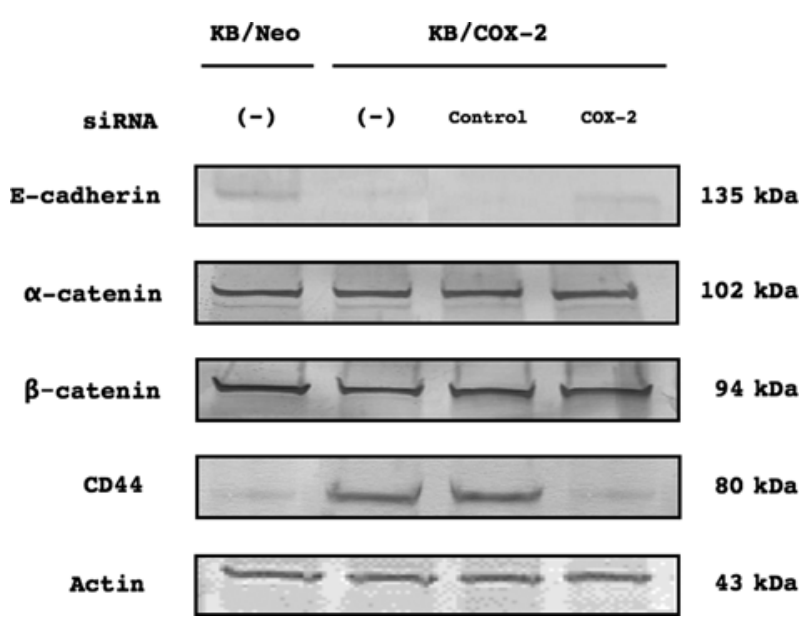

Figure 3. Expression of four proteins as representative adhesion molecules was examined in both cells by Western blotting.

COX-2 expression in vitro, we next examined the expression of adhesion molecules in both cell types (Fig. 3). When expression of E-cadherin, $\alpha$-catenin, $\beta$-catenin and CD44 was examined, there was no difference in $\alpha$ - and $\beta$-catenin between $\mathrm{KB} / \mathrm{COX}-2$ and $\mathrm{KB} / \mathrm{Neo}$. However, expression of $\mathrm{E}$ cadherin was detected in $\mathrm{KB} / \mathrm{Neo}$, but not in $\mathrm{KB} / \mathrm{COX}-2$. In contrast, expression of CD44 was markedly increased in $\mathrm{KB} / \mathrm{COX}-2$ as compared to $\mathrm{KB} / \mathrm{Neo}$. Although treatment with COX-2 siRNA showed no effect on expression of $\alpha$ - and B-catenin, the increased expression of CD44 was completely suppressed by COX-2 siRNA treatment as compared to control siRNA treatment. In addition, expression of Ecadherin in $\mathrm{KB} / \mathrm{COX}-2$ became detectable by $\mathrm{COX}-2$ siRNA treatment.

Stimulation of tumor growth by COX-2 overexpression. As COX-2 overexpression resulted in increased CD44 expression,

A

B

C
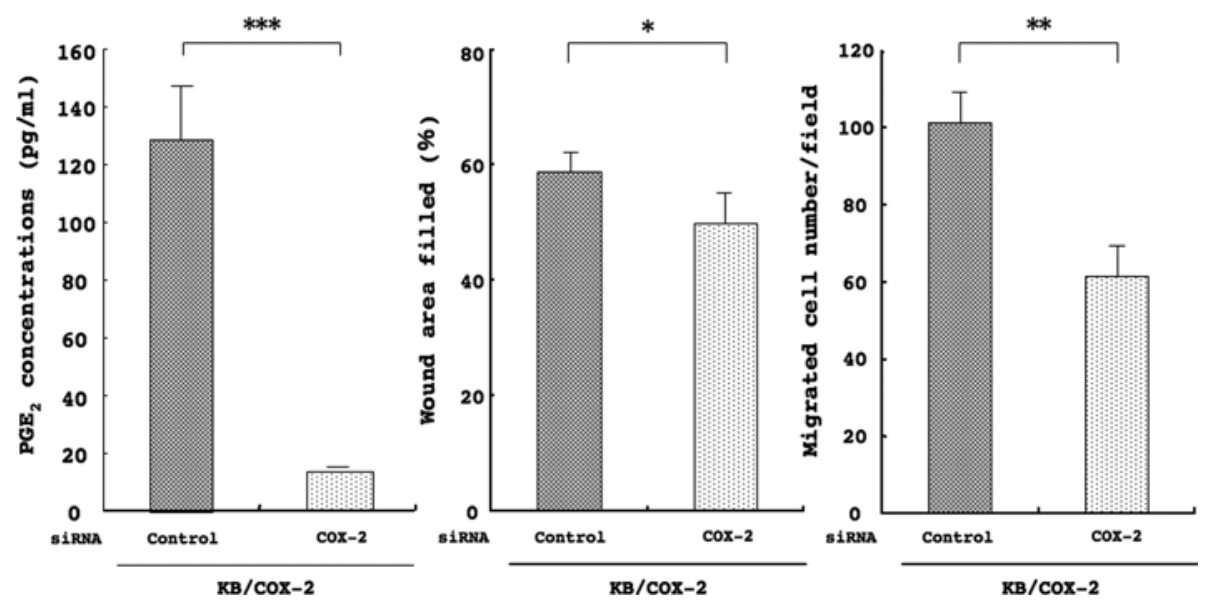

Figure 2. Inhibitory effect of COX-2 siRNA treatment on $\mathrm{PGE}_{2}$ production and cell motility. (A) $\mathrm{PGE}_{2}$ immunoassay was performed as indicated in a protocol of prostaglandin E2 EIA kit (Cayman Chemical) as described previously (16). (B) Wound healing assay was performed using 60-mm fibronectin-coated dishes (Asahi Techno Glass Co.) and (C) invasion assay was carried out using BioCoat Matrigel Invasion Chambers (Becton-Dickinson Labware) as described previously (11). ${ }^{*} \mathrm{P}<0.05,{ }^{* *} \mathrm{P}<0.01,{ }^{* * *} \mathrm{P}<0.005$. 
Table I. Onset of tumor formation and tumor growth by subcutaneous inoculation of cells in nude mice.

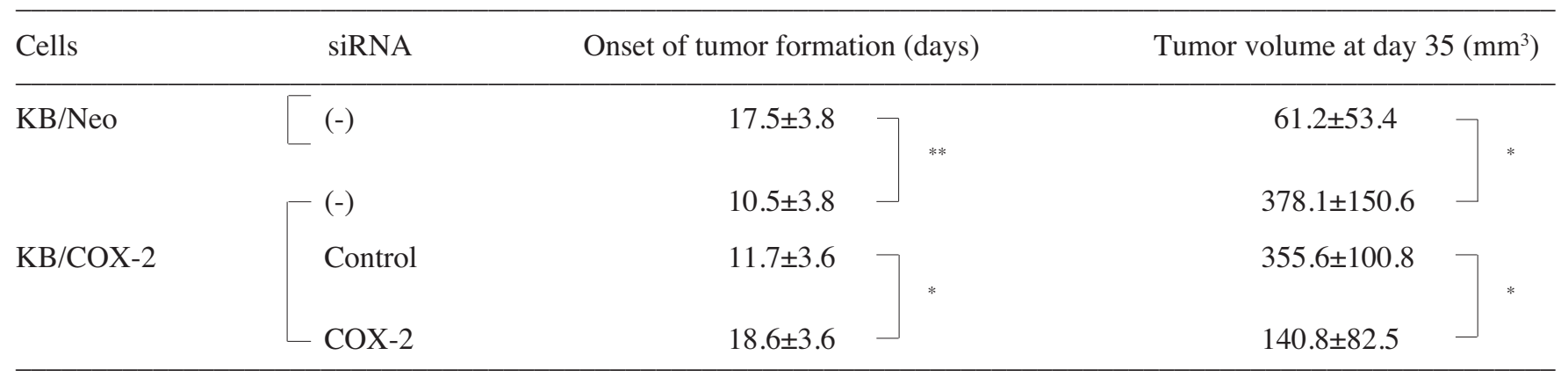

Cells $\left[10^{6} / 0.1 \mathrm{ml}\right.$ PBS (-)] were inoculated into the flank of 6-week-old female nude mice (BALB/C nu/nu, $\mathrm{n}=6$ ). Tumor formation at the inoculated sites was observed for 7 weeks. ${ }^{*} \mathrm{P}<0.05,{ }^{* *} \mathrm{P}<0.01$.

A

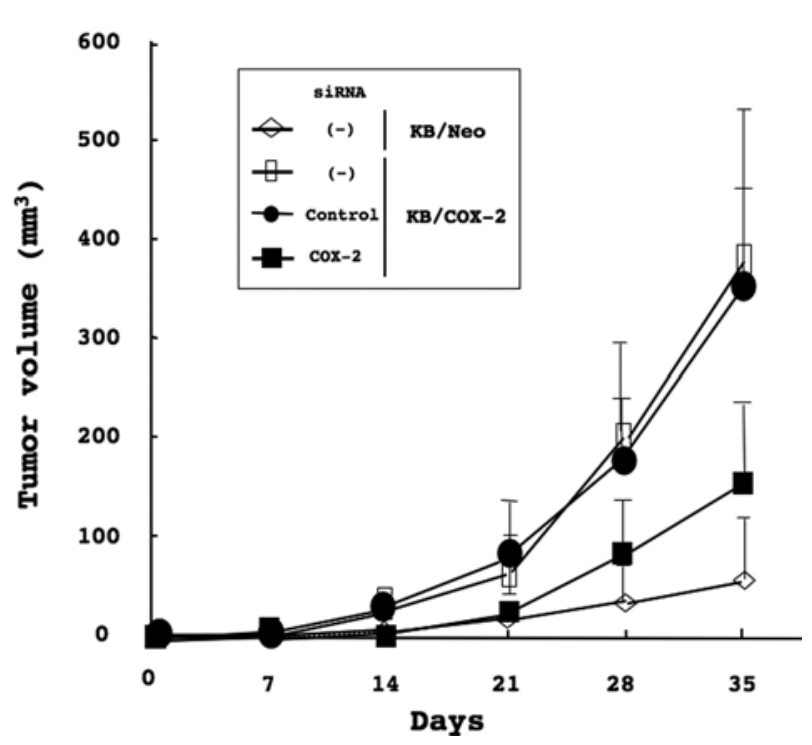

B

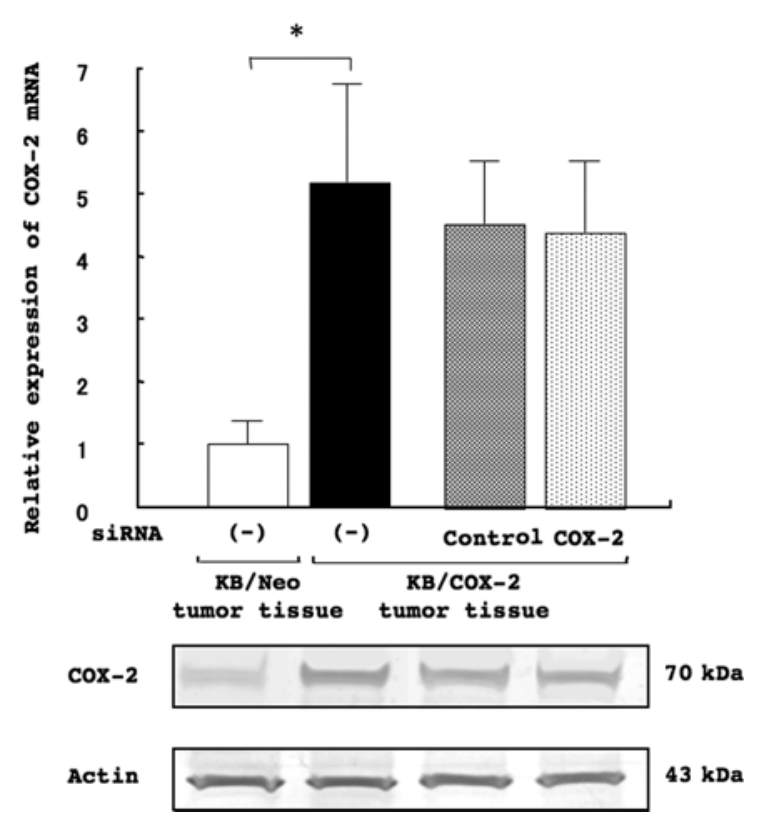

Figure 4. Growth curves of tumors produced by subcutaneous inoculation of cells in nude mice and expression of COX-2 in each tumor. (A) Tumor growth curves produced by subcutaneous inoculation of cells in nude mice. Data represent mean \pm SD of 6 mice. (B) Expression of COX-2 protein and mRNA in each tumor tissue that was obtained by subcutaneous inoculation. ${ }^{*} \mathrm{P}<0.005$.

we next examined the inhibitory effect on COX-2 in vivo. The onset of tumor formation and tumor growth in nude mice were examined by subcutaneous inoculation with $1 \times 10^{6}$ cells $/ 0.1 \mathrm{ml}$ PBS (-). Although all nude mice developed tumors, the onset of tumor formation was 7 days earlier in the mice inoculated with $\mathrm{KB} / \mathrm{COX}-2$ than in those with $\mathrm{KB} / \mathrm{Neo}$, and $\mathrm{COX}-2$ siRNA treatment delayed the onset of tumor formation for 7 days as compared to control siRNA treatment. In addition, tumor volume of $\mathrm{KB} / \mathrm{COX}-2$ at day 35 after inoculation showed about 6-fold increase as compared to $\mathrm{KB} / \mathrm{Neo}$, and that of COX-2 siRNA-treated KB/COX-2 showed about $60 \%$ decrease as compared to control siRNA (Table I, Fig. 4A).

Expression of COX-2 mRNA in $\mathrm{KB} / \mathrm{COX}-2$ tumor tissue formed in nude mice showed about 5 -fold increase as compared to $\mathrm{KB} / \mathrm{Neo}$ tumor tissue. Although tumor growth was retarded by COX-2 siRNA treatment, expression of
COX-2 mRNA in COX-2 siRNA-treated tumor tissue was almost the same as control siRNA-treated tissue (Fig. 4B).

Elevated metastatic potential by COX-2 overexpression and inhibition with COX-2 siRNA. We examined the metastatic potential to the regional lymph nodes in nude mice by orthotopic inoculation to the masseter muscle with $1 \times 10^{5}$ cells in $0.1 \mathrm{ml}$ PBS (-) (Table II). All nude mice developed tumors at inoculated sites. In $\mathrm{KB} / \mathrm{COX}-2$ inoculation, metastasis to the regional lymph nodes occurred in 2 out of 15 mice, and metastasis to the lung in 3 out of 15 mice. In $\mathrm{KB} / \mathrm{Neo}$ inoculation, metastasis to the lymph nodes occurred in only one out of 15 and no metastasis to the lung was found. Then, we examined the inhibitory effect of COX-2 siRNA on metastatic potential to the lymph nodes in $\mathrm{KB} / \mathrm{COX}-2$ cells. In control siRNA-treated $\mathrm{KB} / \mathrm{COX}-2$ inoculation, metastasis to 
Table II. Metastases to lymph nodes and lung by orthotopic transplantation of cells in nude mice.

\begin{tabular}{|c|c|c|c|}
\hline Cells & siRNA & Lymph node metastases (\%) & Lung metastases (\%) \\
\hline \multirow[t]{2}{*}{$\mathrm{KB} / \mathrm{Neo}$} & [ $(-)$ & $1 / 15$ & $0 / 15 \quad(0)$ \\
\hline & {$[(-)$} & $2 / 15(13)$ & $3 / 15(20)$ \\
\hline \multirow[t]{2}{*}{$\mathrm{KB} / \mathrm{COX}-2$} & Control & $1 / 10(10)$ & $2 / 10(20)$ \\
\hline & $\angle \mathrm{COX}-2$ & $0 / 10 \quad(0)$ & $0 / 10 \quad(0)$ \\
\hline
\end{tabular}

Cells $\left[10^{5} / 0.1 \mathrm{ml}\right.$ PBS (-) $]$ were inoculated into the masseter mascle of nude mice. After 7 weeks, mice were sacrificed and metastatic lesions were examined macroscopically and confirmed microscopically.

Table III. Distant metastases by intra-cardiac injection of cells in nude mice.

\begin{tabular}{|c|c|c|}
\hline Cells & siRNA & Lung metastases $(\%)$ \\
\hline \multirow[t]{2}{*}{$\mathrm{KB} / \mathrm{Neo}$} & $(-)$ & $1 / 10(10)$ \\
\hline & $(-)$ & $8 / 10(80)-$ \\
\hline \multirow[t]{2}{*}{$\mathrm{KB} / \mathrm{COX}-2$} & Control & $5 / 10(50)$ \\
\hline & - COX -2 & $0 / 10 \quad(0)-$ \\
\hline
\end{tabular}

Cells $\left[10^{5} / 0.1 \mathrm{ml}\right.$ PBS (-)] were injected into the left cardiac ventricle of nude mice. After 7 weeks, mice were sacrificed and metastatic lesions were examined macroscopically and confirmed microscopically. ${ }^{*} \mathrm{P}<0.01$.

the lymph nodes occurred in 1 out of 10 , and metastasis to the lung occurred in 2 out of 10 . In COX-2 siRNA-treated $\mathrm{KB} / \mathrm{COX}-2$ inoculation, no metastasis to the lymph nodes or lung was found.

In the orthotopic inoculation mentioned above, the number of mice with lung metastasis was greater than that with regional lymph node metastasis. This fact suggests that metastasis to the lung may occur via hematogenous but not lymphatic route. Therefore, we examined the hematogenous metastatic potential of cells using intra-cardiac injection model with $1 \times 10^{5}$ cells in $0.1 \mathrm{ml}$ PBS (-). In KB/COX-2 injection into the left cardiac ventricle of mice, the mice developed metastases to multiple organs; lung, stomach, femur, mandible, kidney, pancreas and adrenal gland. In $\mathrm{KB} / \mathrm{Neo}$ injection, no metastases occurred except for only one metastasis to femur bone out of 10 mice.

Then, we examined the inhibitory effect of COX-2 siRNA on hematogenous metastatic potential in $\mathrm{KB} / \mathrm{COX}-2$ cells. In control siRNA treatment, the mice developed metastases in 5 out of 10, whereas no metastases was found in COX-2 siRNA treatment (Table III).

Increased tumorigenicity and colony forming ability by COX-2 overexpression. It is essential that the cells directly injected into a blood stream adhere and grow in the distant metastatic sites such as the lung and bone. Thus, we speculated that COX-2 overexpression confer the increased ability to adhere and grow. The tumorigenicity by inoculation with various cell number was examined (Table IV).

When $1 \times 10^{6}$ cells were inoculated subcutaneously into the flanks of nude mice, all mice developed tumors at inoculated sites. When $1 \times 10^{5}$ cells were inoculated, KB/COX-2 produced tumors in all mice, but $\mathrm{KB} / \mathrm{Neo}$ produced no tumors. Then, we examined the inhibitory effect of COX-2 siRNA on tumorigenicity of $\mathrm{KB} / \mathrm{COX}-2$. When $1 \times 10^{5}$ cells were inoculated subcutaneously into the flanks of mice, control siRNA-

Table IV. Tumorigenicity by subcutaneous inoculation of cells in nude mice.

\begin{tabular}{|c|c|c|c|c|c|c|}
\hline \multirow[b]{2}{*}{ Cells } & \multirow[b]{2}{*}{ siRNA } & \multicolumn{5}{|c|}{ No. of cells inoculated } \\
\hline & & $1 \times 10^{4}(\%)$ & $3 \times 10^{4}(\%)$ & $1 \times 10^{5}(\%)$ & $5 \times 10^{5}(\%)$ & $1 \times 10^{6}(\%)$ \\
\hline \multirow[t]{2}{*}{$\mathrm{KB} / \mathrm{Neo}$} & {$[(-)$} & $0 / 3(0)$ & $0 / 3 \quad(0)$ & $0 / 6 \quad(0)$ & $2 / 6$ & $6 / 6(100)$ \\
\hline & {$[(-)$} & $0 / 3(0)$ & $1 / 3(33)$ & 6/6 (100) & $6 / 6(100)$ & $6 / 6(100)$ \\
\hline \multirow[t]{2}{*}{$\mathrm{KB} / \mathrm{COX}-2$} & Control & & & $3 / 6 \quad(50)$ & $5 / 6 \quad(83)$ & $6 / 6(100)$ \\
\hline & - COX-2 & & & $0 / 6 \quad(0)$ & $2 / 6 \quad(33)$ & $6 / 6(100)$ \\
\hline
\end{tabular}

Cells were inoculated into the flank of nude mice at cell number indicated. Tumor formation at inoculated sites was observed for 7 weeks. 
treated $\mathrm{KB} / \mathrm{COX}-2$ produced tumors in half of the mice, but COX-2 siRNA-treated $\mathrm{KB} / \mathrm{COX}-2$ produced no tumor.

In addition, clonogenic assay showed that although the colony forming ability of $\mathrm{KB} / \mathrm{COX}-2$ was higher than that of $\mathrm{KB} / \mathrm{Neo}(\mathrm{KB} / \mathrm{COX}-2 ; 82.1 \pm 9.6 \%, \mathrm{~KB} / \mathrm{Neo} ; 44 \pm 6.5 \%$, $\mathrm{P}<0.005), \mathrm{COX}-2$ siRNA treatment significantly inhibited colony formation by $50 \%$ in $\mathrm{KB} / \mathrm{COX}-2$ cells (control siRNA; $17.2 \pm 2.9 \%, \mathrm{COX}-2$ siRNA; $8.3 \pm 1.4 \%, \mathrm{P}<0.05)$.

\section{Discussion}

Many clinical and experimental studies have shown that COX-2 expression is associated with not only carcinogenesis but also local invasion and metastasis. However, few studies have been reported concerning the relation between COX-2 expression and metastasis of tumor cells in head and neck carcinoma (16-18). The significance of COX-2 expression in relation to tumor cell migration, invasion and metastasis of head and neck carcinoma is still poorly understood.

In this study, we have demonstrated a significant reduction of COX-2 levels overexpressed in KB/COX-2 using siRNA strategy, which can knock down the targeted genes with great specificity. We have also shown that treatment of $\mathrm{KB} / \mathrm{COX}-2$ with COX-2 siRNA has a marked inhibitory effect on cell migration, cell invasion, tumorigenicity, tumor growth and metastasis. We focused on the role of COX-2 in metastatic potential by using orthotopic inoculation or injection into the left cardiac ventricle of nude mice with $\mathrm{KB} / \mathrm{COX}-2$ and $\mathrm{KB}$ / Neo. Orthotopic inoculation of tumor cells in nude mice is well known as a spontaneous metastasis model $(19,20)$. On the other hand, metastasis to liver by injection of tumor cells to portal vein or spleen $(21,22)$ and metastasis to lung by injection of tumor cells to tail vein (20) are also reported as experimental metastasis models. Although an intra-cardiac injection of tumor cells $(23,24)$ is easier to make metastasis than other models, it is uncommon because of the technical difficulty. When injected into the left cardiac ventricle of mice, $\mathrm{KB} / \mathrm{COX}-2$ developed metastases to multiple organ such as lung, stomach, femur and so on whereas $\mathrm{KB} / \mathrm{Neo}$ was hardly found to develop metastases. On the other hand, the number of metastasis to lymph nodes was less than that to the lung in orthotopic inoculation. These findings suggested that metastasis to the lung occurred via hematogenous but not lymphatic route.

In the present study, we confirmed that COX-2 overexpression promotes hematogenous metastasis, but the precise mechanisms are still unclear. Since $\mathrm{KB} / \mathrm{COX}-2$ showed very high tumorigenic activity as compared to $\mathrm{KB} / \mathrm{Neo}$, we supposed that $\mathrm{KB} / \mathrm{COX}-2$ has a clear advantage exceeding $\mathrm{KB} /$ Neo in formation of metastasis by injection of small number of cells into a blood stream. As metastasis-related molecules, CXCR4 is a well-known chemokine which is a receptor for stromal cell-derived factor- $1 \alpha(\mathrm{SDF}-1 \alpha)$ and has been shown to be primarily involved in the distant metastasis of several types of cancer (25-27). We have recently reported that CXCR4 expression and metastatic potential are closely related in adenoid cystic carcinoma (ACC) (28). When we examined the expression of $\mathrm{CXCR} 4$ in $\mathrm{KB} / \mathrm{COX}-2$ and $\mathrm{KB} / \mathrm{Neo}$, there was no difference though CXCR4 was expressed in both cells (data not shown). In addition, we also speculated that expression of the adhesion molecules in tumor cells may be relevant to metastasis formation in other organs.

It has been reported that many adhesion molecules contribute to metastasis. In the present study, we examined the expression of E-cadherin, $\alpha$-catenin, $\beta$-catenin and CD44 as representative molecules. Consequently, we found that expression of CD44 was markedly increased in $\mathrm{KB} / \mathrm{COX}-2$ as compared to $\mathrm{KB} / \mathrm{Neo}$, and expression of E-cadherin was detected in $\mathrm{KB} / \mathrm{Neo}$, but not in $\mathrm{KB} / \mathrm{COX}-2$. Treatment with $\mathrm{COX}-2$ siRNA resulted in suppression of CD44 expression and detectable expression of E-cadherin in $\mathrm{KB} / \mathrm{COX}-2$. E-cadherin is a direct mediator of cell-cell adhesive interactions, and the cytoplasmic tail of E-cadherin is tethered, via $\alpha$-catenin and ß-catenin, to the actin cytoskeleton to form cell junctions. Therefore, loss of E-cadherin causes detachment of tumor cells to lead to early invasion and metastasis (29). CD44 is also a cell surface adhesion molecule that mediates diverse function. Experimental evidence suggests that ligation of CD44 on the cell surface induces cell detachment and migration in a variety of cells $(30,31)$. In addition, mounting evidence suggests that CD44 is aberrantly expressed in many human tumors (32). In certain cases, such as with colorectal carcinomas, the expression of CD44 confers metastatic potential in vivo $(33,34)$. Furthermore, CD44 serves to induce co-clustering with MMPs and can promote MMPs activity and tumor invasion (35-37). Kinugasa et al reported that the COX-2 inhibitor NS-398 and COX-2 antisense oligonucleotide suppressed the invasiveness of oral squamous cell carcinoma cell lines in a Matrigel invasion assay via down-regulation of MMP-2, MT1-MMP and CD44 (38). We also reported previously that $\mathrm{KB} / \mathrm{COX}-2$ increased cell migration and invasion via up-regulation of MMP-9, MMP-2 and MT1MMP and down-regulation of TIMP-1 and TIMP-2 (11).

In conclusion, our results demonstrated that overexpression of COX-2 increased tumorigenicity and hematogenous metastasis via down-regulating E-cadherin and up-regulating CD44 expressions in KB cells. The positive correlation of metastatic potential and COX-2 overexpression indicates that COX-2 may become a target molecule for regulating metastases of oral cancer.

\section{Acknowledgements}

This study was supported by a Grant-in-Aid for Scientific Research from the Ministry of Education, Science and Culture of Japan (No.17592122 to H.K. and No.15390630 to M.U.), and Grant-in-Aid for Researchers, Hyogo College of Medicine to H.K.

\section{References}

1. Kargman SL, O'Neill GP, Vickers PJ, Evans JF, Mancini JA and Jothy S: Expression of prostaglandin $\mathrm{G} / \mathrm{H}$ synthase-1 and -2 protein in human colon cancer. Cancer Res 55: 2556-2559, 1995.

2. Ristimaki A, Honkanen N, Jankala H, Sipponen P and Harkonen $\mathrm{M}$ : Expression of cyclooxygenase-2 in human gastric carcinoma. Cancer Res 57: 1276-1280, 1997.

3. Parrett ML, Harris R, Joarder FS, Ross MS, Clausen KP and Robertson FM: Cyclooxygenase-2 gene expression in human breast cancer. Int J Oncol 10: 503-507, 1997.

4. Hida T, Yatabe Y, Achiwa H, et al: Increased expression of cyclooxygenase 2 occurs frequently in human lung cancers, specifically in adenocarcinomas. Cancer Res 58: 3761-3764, 1998. 
5. Mestre JR, Subbaramaiah K, Sacks PG, Schantz SP, Tanabe T, Inoue $\mathrm{H}$ and Dannenberg AJ: Retinoids suppress epidermal growth factor-induced transcription of cyclooxygenase- 2 in human oral squamous carcinoma cells. Cancer Res 57: 2890-2895, 1997.

6. Chan G, Boyle JO, Yang EK, et al: Cyclooxygenase-2 expression is up-regulated in squamous cell carcinoma of the head and neck. Cancer Res 59: 991-994, 1999.

7. Nishimura G, Yanoma S, Mizuno H, Kawakami K and Tsukuda M: A selective cyclooxygenase-2 inhibitor suppresses tumor growth in nude mouse xenografted with human head and neck squamous carcinoma cells. Jpn J Cancer Res 90: 1152-1162, 1999.

8. Sakurai K, Urade M, Noguchi K, et al: Increased expression of cyclooxygenase- 2 in human salivary gland tumors. Pathol Int 51: 762-769, 2001

9. Tsujii M, Kawano S and DuBois RN: Cyclooxygenase-2 expression in human colon cancer cells increases metastatic potential. Proc Natl Acad Sci USA 94: 3336-3340, 1997.

10. Tomozawa S, Tsuno NH, Sunami E, et al: Cyclooxygenase-2 overexpression correlates with tumour recurrence, especially haematogenous metastasis, of colorectal cancer. Br J Cancer 83: 324-328, 2000

11. Takaoka K, Kishimoto H, Segawa E, et al: Elevated cell migration, invasion and tumorigenicity in human $\mathrm{KB}$ carcinoma cells transfected with COX-2 cDNA. Int J Oncol 29: 1095-1101, 2006.

12. Ovejera AA, Houchens DP and Baker AD: Chemotherapy of human tumor xenografts in genetically athymic mice. Ann Clin Lab Sci 8: 50-56, 1978.

13. Kishimoto H, Wang Z, Bhat-Nakshatri P, Chang D, Clarke R and Nakshatri H: The p160 family coactivators regulate breast cancer cell proliferation and invasion through autocrine/ paracrine activity of SDF- $1 \alpha /$ CXCL12. Carcinogenesis 26 : 1706-1715, 2005.

14. Boyle DL, Rosengren S, Bugbee W, Kavanaugh A and Firestein GS: Quantitative biomarker analysis of synovial gene expression by real-time PCR. Arthritis Res Ther 5: 352-360, 2003.

15. Hashitani S, Urade M, Nishimura N, Maeda T, Takaoka K, Noguchi K and Sakurai K: Apoptosis induction enhancement of anticancer drugs by celecoxib, a selective cyclooxygenase-2 inhibitor, in human head neck carcinoma cell lines. Int J Oncol 23: $665-672,2003$

16. Sakurai K, Urade M, Noguchi K, Hashitani S, Takaoka K, Segawa E and Kishimoto H: Prognostic significance of cyclooxygenase- 2 and DNA topoisomerase II $\alpha$ expression in oral carcinoma. Head Neck 29: 1002-1009, 2007.

17. Gallo O, Franchi A, Magnelli L, et al: Cyclooxygenase-2 pathway correlates with VEGF expression in head and neck cancer. Implications for tumor angiogenesis and metastasis. Neoplasia 3: 53-61, 2001.

18. Lin DT, Subbaramaiah K, Shah JP, Dannenberg AJ and Boyle JO: Cyclooxygenase-2: a novel molecular target for the prevention and treatment of head and neck cancer. Head Neck 24: 792-799, 2002.

19. Uchida D, Begum NM, Tomizuka Y, Bando T, Almofti A, Yoshida $\mathrm{H}$ and Sato $\mathrm{M}$ : Acquisition of lymph node, but not distant metastatic potentials, by the overexpression of CXCR4 in human oral squamous cell carcinoma. Lab Invest 84: 1538-1546, 2004

20. Roche-Nagle G, Connolly EM, Eng M, Bouchier-Hayes DJ and Harmey JH: Antimetastatic activity of a cyclooxygenase-2 inhibitor. Br J Cancer 91: 359-365, 2004.

21. Yamauchi T, Watanabe M, Hasegawa $\mathrm{H}$, et al: The potential for a selective cyclooxygenase-2 inhibitor in the prevention of liver metastasis in human colorectal cancer. Anticancer Res 23 245-249, 2003.
22. Yao M, Lam EC, Kelly CR, Zhou W and Wolfe MM: Cyclooxygenase-2 selective inhibition with NS-398 suppresses proliferation and invasiveness and delays liver metastasis in colorectal cancer. Br J Cancer 90: 712-719, 2004.

23. Sharp JA, Waltham M, Williams ED, Henderson MA and Thompson EW: Transfection of MDA-MB-231 human breast carcinoma cells with bone sialoprotein (BSP) stimulates migration and invasion in vitro and growth of primary and secondary tumors in nude mice. Clin Exp Metastasis 21: 19-29, 2004.

24. Zhang JH, Tang J, Wang J, Ma W, Zheng W, Yoneda T and Chen J: Overexpression of bone sialoprotein enhances bone metastasis of human breast cancer cells in a mouse model. Int J Oncol 23: 1043-1048, 2003.

25. Muller A, Homey B, Soto H, et al: Involvement of chemokine receptors in breast cancer metastasis. Nature 410: 50-56, 2001.

26. Taichman RS, Cooper C, Keller ET, Pienta KJ, Taichman NS and McCauley LK: Use of the stromal cell-derived factor-1/ CXCR4 pathway in prostate cancer metastasis to bone. Cancer Res 62: 1832-1837, 2002.

27. Schrader AJ, Lechner O, Templin M, et al: CXCR4/CXCL12 expression and signalling in kidney cancer. Br J Cancer 86: $1250-1256,2002$

28. Zushi Y, Noguchi K, Hashitani S, et al: Relations among expression of CXCR4, histological patterns and metastatic potential in adenoid cystic carcinoma of the head and neck. Int J Oncol 33: 1133-1139, 2008.

29. Chiang AC and Massagué J: Molecular basis of metastasis. N Engl J Med 359: 2814-2823, 2008.

30. Dohadwala M, Luo J, Zhu L, et al: Non-small cell lung cancer cyclooxygenase-2-dependent invasion is mediated by CD44. J Biochem 276: 20809-20812, 2001.

31. Tian B, Takasu T and Henke C: Functional role of cyclin A on induction of fibroblast apoptosis due to ligation of CD44 matrix receptor by anti-CD44 antibody. Exp Cell Res 257: 135-144, 2000.

32. Ponta H, Sherman L and Herrlich PA: CD44: from adhesion molecules to signalling regulators. Nat Rev Mol Cell Biol 4: 33-45, 2003.

33. Harada N, Mizoi T, Kinouchi M, et al: Introduction of antisense CD44S CDNA down-regulates expression of overall CD44 isoforms and inhibits tumor growth and metastasis in highly metastatic colon carcinoma cells. Int J Cancer 91: 67-75, 2001.

34. Reeder JA, Gotley DC, Walsh MD, Fawcett J and Antalis TM: Expression of antisense CD44 variant 6 inhibits colorectal tumor metastasis and tumor growth in a wound environment. Cancer Res 58: 3719-3726, 1998.

35. Yu Q and Stamenkovic I: Localization of matrix metalloproteinase 9 to the cell surface provides a mechanism for CD44mediated tumor invasion. Genes Dev 13: 35-48, 1999.

36. Takahashi $\mathrm{K}$, Eto $\mathrm{H}$ and Tanabe KK: Involvement of CD44 in matrix metalloproteinase-2 regulation in human melanoma cells. Int J Cancer 80: 387-395, 1999.

37. Zhang Y, Thant AA, Machida K, et al: Hyaluronan-CD44s signaling regulates matrix metalloproteinase-2 secretion in a human lung carcinoma cell line QG90. Cancer Res 62: 3962-3965, 2002.

38. Kinugasa Y, Hatori M, Ito H, Kurihara Y, Ito D and Nagumo M: Inhibition of cyclooxygenase-2 suppresses invasiveness of oral squamous cell carcinoma cell lines via down-regulation of matrix metalloproteinase-2 and CD44. Clin Exp Metastasis 21: 737-745, 2004. 